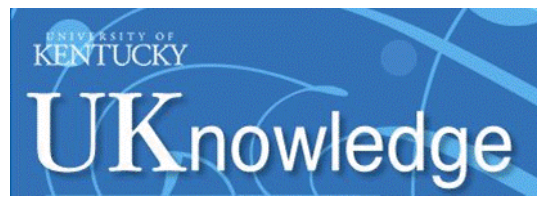

University of Kentucky

UKnowledge

$11-30-2013$

\title{
Dopaminergic Modulation of Memory and Affective Processing in Parkinson Depression
}

Lee X. Blonder

University of Kentucky, Ixblond@uky.edu

John T. Slevin

University of Kentucky, jslevin@uky.edu

Richard J. Kryscio

University of Kentucky, kryscio@uky.edu

Catherine A. Martin

University of Kentucky, catherine.martin@uky.edu

Anders H. Andersen

University of Kentucky, anders@mri.uky.edu

Follow this and additional works at: https://uknowledge.uky.edu/mrisc_facpub

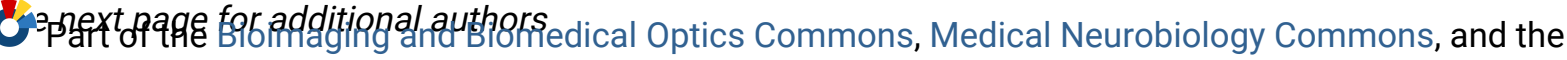
Neurology Commons

Right click to open a feedback form in a new tab to let us know how this document benefits you.

\section{Repository Citation}

Blonder, Lee X.; Slevin, John T.; Kryscio, Richard J.; Martin, Catherine A.; Andersen, Anders H.; Smith, Charles D; and Schmitt, Frederick A., "Dopaminergic Modulation of Memory and Affective Processing in Parkinson Depression" (2013). Magnetic Resonance Imaging and Spectroscopy Center Faculty Publications. 2.

https://uknowledge.uky.edu/mrisc_facpub/2

This Article is brought to you for free and open access by the Magnetic Resonance Imaging and Spectroscopy at UKnowledge. It has been accepted for inclusion in Magnetic Resonance Imaging and Spectroscopy Center Faculty Publications by an authorized administrator of UKnowledge. For more information, please contact 


\section{Dopaminergic Modulation of Memory and Affective Processing in Parkinson Depression}

\section{Digital Object Identifier (DOI)}

http://dx.doi.org/10.1016/j.psychres.2013.06.003

\section{Notes/Citation Information}

Published in Psychiatry Research, v. 210, issue 1, p. 146-149.

(c) 2013 Elsevier Ireland Ltd. All rights reserved.

This manuscript version is made available under the CC-BY-NC-ND 4.0 license

http://creativecommons.org/licenses/by-nc-nd/4.0/

\section{Authors}

Lee X. Blonder, John T. Slevin, Richard J. Kryscio, Catherine A. Martin, Anders H. Andersen, Charles D Smith, and Frederick A. Schmitt 
(C) 2013 Elsevier Ireland Ltd. All rights reserved.

This manuscript version is made available under the CC-BY-NC-ND 4.0 license

http://creativecommons.org/licenses/by-nc-

nd $/ 4.0 /$ 


\title{
Dopaminergic modulation of memory and affective processing in Parkinson depression
}

\author{
Lee X. Blondera,b,c, ${ }^{\star}$, John T. Slevin ${ }^{c, d}$, Richard J. Kryscio ${ }^{a, e, f}$, Catherine A. Marting, Anders \\ H. Andersen ${ }^{h, i}$, Charles D. Smith ${ }^{\mathrm{c}, h, \mathrm{i}}$, and Frederick A. Schmitta ${ }^{\mathrm{a}, \mathrm{b}, \mathrm{c}, \mathrm{g}}$ \\ aSanders-Brown Center on Aging, University of Kentucky, Lexington, KY, U.S.A \\ bDepartment of Behavioral Science, University of Kentucky, Lexington, KY, U.S.A \\ 'Department of Neurology, University of Kentucky, Lexington, KY, U.S.A \\ dVeterans Administration Medical Center, Lexington, KY, U.S.A \\ eDepartment of Statistics, University of Kentucky, Lexington, KY, U.S.A \\ fDepartment of Biostatistics, University of Kentucky, Lexington, KY, U.S.A \\ gDepartment of Psychiatry, University of Kentucky, Lexington, KY, U.S.A \\ hDepartment of Anatomy and Neurobiology, University of Kentucky, Lexington, KY, U.S.A \\ 'Magnetic Resonance Imaging and Spectroscopy Center, University of Kentucky, Lexington, KY., \\ U.S.A
}

\section{Abstract}

Depression is common in Parkinson's disease and is associated with cognitive impairment. Dopaminergic medications are effective in treating the motor symptoms of Parkinson's disease; however, little is known regarding the effects of dopaminergic pharmacotherapy on cognitive function in depressed Parkinson patients. This study examines the neuropsychological effects of dopaminergic pharmacotherapy in Parkinsonian depression. We compared cognitive function in depressed and non-depressed Parkinson patients at two time-points: following overnight withdrawal and after the usual morning regimen of dopaminergic medications. A total of 28 nondemented, right-handed patients with mild to moderate idiopathic Parkinson's disease participated. Ten of these patients were depressed according to DSM IV criteria. Results revealed a statistically significant interaction between depression and medication status on three measures of verbal memory and a facial affect naming task. In all cases, depressed Parkinson's patients performed significantly more poorly while on dopaminergic medication than while off. The opposite pattern emerged for the non-depressed Parkinson's group. The administration of dopaminergic medication to depressed Parkinson patients may carry unintended risks.

\section{Keywords}

Parkinson; mood; cognition; emotion; dopamine

(C) 2013 Elsevier Ireland Ltd. All rights reserved.

*Corresponding Author: Lee X. Blonder, Ph.D., 101 Sanders-Brown Center on Aging, 800 S. Limestone St., University of Kentucky, Lexington, KY 40536-0230, Tel: 859-257-9223; Fax: 858-323-2866, 1xblond@email.uky.edu.

Publisher's Disclaimer: This is a PDF file of an unedited manuscript that has been accepted for publication. As a service to our customers we are providing this early version of the manuscript. The manuscript will undergo copyediting, typesetting, and review of the resulting proof before it is published in its final citable form. Please note that during the production process errors may be discovered which could affect the content, and all legal disclaimers that apply to the journal pertain. 


\section{INTRODUCTION}

Depression is a common and serious co-morbidity in patients with Parkinson's disease (Cummings, 1992; Slaughter et al., 2001; Veazey et al., 2005; Blonder and Slevin, 2011). Cummings (1992) estimated that approximately 40 percent of PD patients suffer from depression. A meta-analysis of depression prevalence in PD based on 36 selected studies found that 17 percent of Parkinson patients had major depressive disorder, 22 percent had minor depression, and 13 percent were dysthymic (Reijnders et al., 2008). While Parkinsonian depression may have a reactive component (Gotham et al., 1986; Lindgren, 1996), evidence indicates it is most likely caused by depletion of brain catecholamines and serotonin and dysregulation of fronto-subcortical connections that regulate mood (Mayberg et al., 1990; Remy et al., 2005).

Depressed PD patients (dPD) often have cognitive deficits, primarily involving executive function and working memory. In particular, studies have shown that dPD patients are impaired relative to non-depressed PD patients on tests of attention and memory, verbal fluency, set-shifting, confrontation naming, and problem-solving (Starkstein et al., 1989; Wertman et al., 1993; Troster et al., 1995a; Troster et al., 1995b; Kuzis et al., 1997; Uekermann et al., 2003; Stefanova et al., 2006). Moreover, depression is associated with what is now recognized as mild cognitive impairment (MCI) in PD. MCI-PD patients often have the non-amnestic variety that is characterized by impairments in executive function (Goldman and Litvan, 2011). In one of the few studies that has explored the effects of antidepressant medication on cognitive function in Parkinsonian depression, Dobkin et al. (2010) found no treatment-related improvements in cognition associated with the administration of the antidepressants paroxetine and nortriptyline, despite successful antidepressant effects.

Although the association between cognitive impairment and depression in PD is welldocumented, little is known regarding the effects of dopaminergic medications on cognitive function in dPD patients. In contrast, numerous studies have suggested that dopaminergic drugs modulate cognitive processes among PD patients generally. For example, dopaminergic replacement therapy has been linked to significant, long-lasting improvement on tests of learning, long-term visual and verbal memory, visuospatial abilities, and frontal lobe tasks (Kulisevsky et al., 2000). Likewise, levodopa withdrawal is associated with impaired performance on tests of frontal lobe function, including planning, working memory, and attentional set-shifting (Lange et al., 1992; Lange et al., 1995; Fournet et al., 2000). Functional neuroimaging research shows that dopaminergic medications alter regional brain response during cognitive task performance in PD patients, but these alterations do not correlate with test performance (Cools et al., 2002; Mattay et al., 2002; Tessitore et al., 2002). Some studies suggest that dopaminergic medications may enhance or impair cognitive function in PD depending upon the nature of the task and basal levels of dopamine (Cools et al., 2001, 2003; Hälbig et al., 2011). In particular, Cools et al. (2003) report that cognitive inflexibility decreases on dopaminergic therapy while impulsivity increases. Hälbig et al. (2011) found that PD patients' performance on emotion recognition and reaction time tasks was significantly worse while "on" versus "off" dopaminergic therapy. None of these studies was designed to examine the specific impact of dopaminergic drugs on cognitive function in Parkinsonian depression, however, and some excluded patients with a history of affective disorders.

The purpose of the present study was to examine dopaminergic modulation of cognitive and affective task performance in depressed Parkinson patients. Based on the literature suggesting that dopaminergic pathways support working memory and affective processing 
and that dopamine agonists may play a role in ameliorating depression in PD (Corrigan et al., 2000; Rektorová et al., 2003; Lemke, 2008; Barone et al., 2010), our a priori hypothesis was that withdrawal of dopaminergic medications is associated with increased depressive mood as well as impairments in cognitive and affective task performance.

\section{METHODS}

\subsection{Subjects}

A total of 28 right-handed, non-demented, idiopathic PD patients (10 women, 18 men) participated in this study. Patients were diagnosed by an American Board of Psychiatry and Neurology-certified neurologist specializing in movement disorders (JTS) using UK Parkinson's Disease Brain Bank Clinical Diagnostic Criteria (Hughes et al., 1992). Only those patients with a diagnosis of mild to moderate idiopathic PD ( $\leq 3$ on the Hoehn and Yahr scale) were eligible to participate. Patients were under treatment with levodopa plus carbidopa either alone or in combination with dopamine agonists. Of the 28 patients, 10 met DSM-IV diagnostic criteria for a depressive disorder (seven had major depressive disorder, three had minor depression). Three of the ten dPD patients were taking selective serotonin re-uptake inhibitors at the time of testing, one patient was also receiving a selective serotonin-norepinephrine re-uptake inhibitor, and six were not receiving anti-depressant medication. Demographic and clinical characteristics of the participants are given in Table 1.

Eligible participants made three visits to the University of Kentucky Medical Center to complete screening and assessment. Prior to either the second or third visit, the patient stopped taking anti-Parkinson medication after the last dose of the previous evening and before midnight. Thus testing commenced at minimum nine hours after the last dose of antiParkinson medication. For the other visit, the patient took medication as prescribed the morning of the session (order counterbalanced across participants). Clinical evaluations were based on the Unified Parkinson's Disease Rating Scale (UPDRS) total on and off scores and UPDRS motor on and off scores. Testing was conducted in an operationally defined off condition: 1) anti-PD medications withheld for approximately 2.0 times the duration of each drug's predicted serum half-life; and 2) prior to the patient's first dose of medication on the day of testing. Testing in the on condition was performed within 1-2 hours after a patient's first dose of anti-PD medication for the day. All participants gave informed consent under an institutionally approved protocol.

\subsection{Procedures}

During the first visit participants underwent cognitive screening, the Structured Clinical Interview for DSM IV, the Hamilton Depression Scale-21 item version (Hedlund and Viewig, 1979) a neurologic examination, the Hoehn and Yahr Scale, and the Unified Parkinson's Disease Rating Scale (UPDRS). The neuropsychological battery, administered during visits two and three, included the Hopkins Verbal Learning Test-Revised, Purdue Pegboard, Benton Test of Facial Recognition, Brief Visuospatial Memory Test-Revised, select subtests of the Delis-Kaplan Executive Function System, Wechsler Adult Intelligence Scale-Revised, Digit Span Forward and Backward, a facial affect naming task consisting of validated photos of individuals expressing happy, sad, angry, frightened, disgusted, and neutral emotions, the Apathy Scale, State-Trait Anxiety Inventory, Geriatric Depression Scale (15-item version), University of Pennsylvania Smell Test, Visual Analogue ratings of mood, and the Positive and Negative Affect Scale. The order of tests differed between visits two and three. We administered alternate test forms when available. 


\section{RESULTS}

To compare gender composition as well as the proportion of depressed and non-depressed PD patients on dopamine agonists, we used the chi-square test. The remaining demographic and clinical characteristics of depressed and non-depressed PD patients were compared using two-sampled t tests (see Table 1). Results indicated that there were no statistically significant differences between the depressed and non-depressed PD groups on gender, education, or Dementia Rating Scale scaled scores. DPD patients were significantly younger and scored significantly lower than non-depressed PD patients on the National Adult Reading Test- revised (NART-R), a measure of pre-morbid intelligence. The following clinical characteristics did not differ between depressed and non-depressed PD patients: Hoehn and Yahr stage of illness, the Unified Parkinson Disease Rating Scale Motor or Tremor subscales, activities of daily living abilities, percent of patients taking dopamine agonists, and levodopa-equivalent daily dose of medication (Nutt et al., 2003).

As expected, dPD patients were significantly more depressed than non-dPD patients on the Hamilton Depression and Geriatric Depression Scales (GDS). Depression severity as measured by the GDS was significantly greater while dPD patients were on dopaminergic medications as compared to off ( $6.2 \pm 1.0$ on PD medications versus $5.2 \pm 1.0$ off, $p=$ $0.049)$. There were no statistically significant differences in GDS scores among nondepressed PD patients on versus off PD medications.

To examine the effect of dopaminergic pharmacotherapy on neuropsychological test performance as a function of PD mood status, we compared mean response using an analysis of covariance for a crossover design with depression as the between subjects factor (present or absent) and dopaminergic medication status as the within subjects factor (on or off), tested in random order. Age and NART-R Full scale IQ scores served as covariates. Interactions between depression and medication status were statistically significant for the facial affect naming test $(\mathrm{p}=0.016)$ and the Hopkins Verbal Learning-revised Total Recall $(\mathrm{p}=0.011)$, Delayed Recall $(\mathrm{p}=0.010)$, and Recognition/Discrimination sub-scores $(\mathrm{p}=0.045)$. Figure 1 displays least squares means and standard errors for the Facial Affect Naming Test. Figure 2 displays least squares means and standard errors for Hopkins Verbal Learningrevised Total Recall and Delayed Recall. The Hopkins Verbal Learning-revisedRecognition/Discrimination test showed the same pattern of findings as did the other measures.

\section{DISCUSSION}

These results indicate that in $\mathrm{dPD}$ patients, dopaminergic medications are associated with poorer performance in verbal memory and affective processing. In particular, dPD patient report increased depression severity and perform more poorly on tests of verbal memory and affect recognition while on dopaminergic drugs than while off. Dopaminergic medications have the opposite effect on memory and affect recognition in non-depressed PD patients in that performance on these tasks is enhanced by these drugs.

To our knowledge, this is the first report to suggest that dopaminergic medications universally prescribed to treat Parkinsonian motor symptoms may have deleterious effects on non-motor function among dPD patients. These negative outcomes do not occur in nondepressed PD patients; memory and affect recognition improve in non-depressed PD patients while taking dopaminergic medications. These results underscore the need to consider depressed and non-depressed PD patients independently in studies designed to evaluate the effects of dopaminergic pharmacotherapy on cognitive and affective processing in PD. 
The mechanism underlying these findings remains uncertain. Past research has suggested an inverted $U$-shaped relationship between cognitive function and dopamine in the prefrontal cortex, with both excessive and inadequate levels impairing performance (Cools and D'Esposito, 2011). Genetic polymorphisms that influence neurotransmitter activity may contribute to this response. For example, catechol $O$-methyltransferase (COMT) is an enzyme that regulates dopamine and other catecholamines in various brain regions. The COMT gene has a common functional polymorphism (rs4680) that results in a methionine (met) to valine ( $\mathrm{val}$ ) substitution at codon 158 (Lachman et al., 1996). The low activity met allele of COMTrs4680 is linked to higher baseline levels of dopamine in the prefrontal cortex, as well as to enhanced working memory, executive function, attention, and reactivity to negative emotional stimuli on fMRI (Smolka et al., 2005; Heinz and Smolka, 2006). The met allele is also associated with a higher risk of depression (Ohara et al., 1998; Aberg et al., 2011), anxiety (Enoch et al., 2003), bipolar disorder (Mynett-Johnson et al., 1998), and obsessive compulsive disorder (Karayiorgou et al., 1999), and has been inconsistently linked to an increased risk of PD as well as variability in individual response to levodopa therapy (Kunugi et al., 1997; Tai and Wu, 2002; Contin et al., 2005; Kiyohara et al., 2011).

Neuroimaging studies in healthy individuals suggest that the administration of dopamine modulators such as amphetamine to individuals homozygous for the met allele results in a decline in cortical efficiency on working memory tasks (Mattay et al., 2003), supporting the inverted $U$ relationship described above. In contrast, administration of amphetamine to val homozygotes results in improved cortical efficiency. Although it is premature to suggest that polymorphisms in genes that control dopamine function during cognitive processing may underlie the medication effects we observed among dPD patients, this area is worthy of future research.

This study has identified a serious and previously unreported side-effect of dopaminergic pharmacotherapy in $\mathrm{dPD}$. Clinicians should be alert to these outcomes and monitor dPD patients' cognitive and affective function. However, additional studies in larger samples are required before these results should be used to alter treatment plans. In particular, future research should examine (1) the presence of dopaminergic medication-associated increases in depression severity and their possible relationship to changes in cognitive performance on and off dopaminergic drugs; (2) the pharmacogenetics underlying these effects, and (3) alternative medication regimens that will produce consistent cognitive and affective benefit in both depressed and non-depressed PD patients.

\section{Acknowledgments}

The research reported in this publication was supported by the National Institute of Mental Health and the National Institute of Neurological Disorders and Stroke grant R01MH78228 and by the Department of Veterans Affairs.

The content is solely the responsibility of the authors and does not necessarily represent the official views of the National Institutes of Health.

\section{REFERENCES}

Aberg E, Fandino-Losada A, Sjoholm LK, Forsell Y, Lavebratt C. The functional Val158Met polymorphism in catechol-O-methyltransferase (COMT) is associated with depression and motivation in men from a Swedish population-based study. Journal of Affective Disorders. 2011; 129:158-166. [PubMed: 20828831]

Barone P, Poewe W, Albrecht S, Debieuvre C, Massey D, Rascol O, Tolosa E, Weintraub D. Pramipexole for the treatment of depressive symptoms in patients with Parkinson's disease: a randomised, double-blind, placebo-controlled trial. Lancet Neurology. 2010; 9:573-580. [PubMed: 20452823] 
Blonder LX, Slevin JT. Emotional dysfunction in Parkinson's disease. Behavioral Neurology. 2011; 24:201-217. [PubMed: 21876260]

Contin M, Martinelli P, Mochi M, Riva R, Albani F, Baruzzi A. Genetic polymorphism of catechol-Omethyltransferase and levodopa pharmacokinetic-pharmacodynamic pattern in patients with Parkinson's disease. Movement Disorders. 2005; 20:734-739. [PubMed: 15747357]

Cools R, Barker RA, Sahakian BJ, Robbins TW. Enhanced or impaired cognitive function in Parkinson's disease as a function of dopaminergic medication and task demands. Cerebral Cortex. 2001; 11:1136-1143. [PubMed: 11709484]

Cools R, Barker RA, Sahakian BJ, Robbins TW. L-Dopa medication remediates cognitive inflexibility, but increases impulsivity in patients with Parkinson's disease. Neuropsychologia. 2003; 41:14311441. [PubMed: 12849761]

Cools R, D'Esposito M. Inverted-U-shaped dopamine actions on human working memory and cognitive control. Biological Psychiatry. 2011; 69:e113-e125. [PubMed: 21531388]

Cools R, Stefanova E, Barker RA, Robbins TW, Owen AM. Dopaminergic modulation of high-level cognition in Parkinson's disease: the role of the prefrontal cortex revealed by PET. Brain. 2002; 125:584-594. [PubMed: 11872615]

Corrigan MH, Denahan AQ, Wright CE, Ragual RJ, Evans DL. Comparison of pramipexole, fluoxetine, and placebo in patients with major depression. Depression and Anxiety. 2000; 11:58-65. [PubMed: 10812530]

Cummings JL. Depression and Parkinson's disease: a review. American Journal of Psychiatry. 1992; 149:443-454. [PubMed: 1372794]

Dobkin RD, Menza M, Bienfait KL, Gara M, Marin H, Mark MH, Dicke A, Troster A. The impact of antidepressant treatment on cognitive functioning in depressed patients with Parkinson's disease. Journal of Neuropsychiatry and Clinical Neuroscience. 2010; 22:188-195.

Enoch MA, Xu K, Ferro E, Harris CR, Goldman D. Genetic origins of anxiety in women: a role for a functional catechol-O-methyltransferase polymorphism. Psychiatric Genetics. 2003; 13:33-41. [PubMed: 12605099]

Fournet N, Moreaud O, Roulin JL, Naegele B, Pellat J. Working memory functioning in medicated Parkinson's disease patients and the effect of withdrawal of dopaminergic medication. Neuropsychology. 2000; 14:247-253. [PubMed: 10791864]

Goldman JG, Litvan I. Mild cognitive impairment in Parkinson's disease. Minerva medica. 2011; 102:441-459. [PubMed: 22193376]

Gotham AM, Brown RG, Marsden CD. Depression in Parkinson's disease: a quantitative and qualitative analysis. Journal of Neurology, Neurosurgery, and Psychiatry. 1986; 49:381-389.

Hedlund JL, Viewig BW. The Hamilton rating scale for depression: a comprehensive review. Journal of Operational Psychiatry. 1979; 10:149-165.

Heinz A, Smolka MN. The effects of catechol O-methyltransferase genotype on brain activation elicited by affective stimuli and cognitive tasks. Review of Neuroscience. 2006; 17:359-367.

Hughes AJ, Daniel SE, Kilford L, Lees AJ. Accuracy of clinical diagnosis of idiopathic Parkinson's disease: a clinico-pathological study of 100 cases. Journal of Neurology, Neurosurgery, Psychiatry. 1992; 55:181-184.

Hälbig TD, Assuras S, Creighton J, Borod JC, Tse W, Frisina PG, Voustianiouk A, Gracies JM, Olanow CW. Differential role of dopamine in emotional attention and memory: evidence from Parkinson's disease. Movement Disorders. 2011; 26:1677-1683. [PubMed: 21638322]

Karayiorgou M, Sobin C, Blundell ML, Galke BL, Malinova L, Goldberg P, Ott J, Gogos JA. Familybased association studies support a sexually dimorphic effect of COMT and MAOA on genetic susceptibility to obsessive-compulsive disorder. Biological Psychiatry. 1999; 45:1178-1189. [PubMed: 10331110]

Kiyohara C, Miyake Y, Koyanagi M, Fujimoto T, Shirasawa S, Tanaka K, Fukushima W, Sasaki S, Tsuboi Y, Yamada T, Oeda T, Shimada H, Kawamura N, Sakae N, Fukuyama H, Hirota Y, Nagai M. Genetic polymorphisms involved in dopaminergic neurotransmission and risk for Parkinson's disease in a Japanese population. BMC Neurology. 2011; 11:89. [PubMed: 21781348]

Kulisevsky J, Garcia-Sanchez C, Berthier ML, Barbanoj M, Pascual-Sedano B, Gironell A, EstevezGonzalez A. Chronic effects of dopaminergic replacement on cognitive function in Parkinson's 
disease: a two-year follow-up study of previously untreated patients. Movement Disorders. 2000; 15:613-626. [PubMed: 10928571]

Kunugi H, Nanko S, Ueki A, Otsuka E, Hattori M, Hoda F, Vallada HP, Arranz MJ, Collier DA. High and low activity alleles of catechol-O-methyltransferase gene: ethnic difference and possible association with Parkinson's disease. Neuroscience Letters. 1997; 221:202-204. [PubMed: 9121699]

Kuzis G, Sabe L, Tiberti C, Leiguarda R, Starkstein SE. Cognitive functions in major depression and Parkinson disease. Archives of Neurology. 1997; 54:982-986. [PubMed: 9267973]

Lachman HM, Papolos DF, Saito T, Yu YM, Szumlanski CL, Weinshilboum RM. Human catechol-Omethyltransferase pharmacogenetics: description of a functional polymorphism and its potential application to neuropsychiatric disorders. Pharmacogenetics. 1996; 6:243-250. [PubMed: 8807664]

Lange KW, Paul GM, Naumann M, Gsell W. Dopaminergic effects on cognitive performance in patients with Parkinson's disease. Journal of Neural Transmission Supplement. 1995; 46:423-432. [PubMed: 8821078]

Lange KW, Robbins TW, Marsden CD, James M, Owen AM, Paul GM. L-dopa withdrawal in Parkinson's disease selectively impairs cognitive performance in tests sensitive to frontal lobe dysfunction. Psychopharmacology (Berlin). 1992; 107:394-404. [PubMed: 1615139]

Lemke MR. Dopamine agonists in the treatment of non-motor symptoms of Parkinson's disease: depression. European Journal of Neurology. 2008; 15(Suppl 2):9-14. [PubMed: 18702737]

Lindgren CL. Chronic sorrow in persons with Parkinson's and their spouses. Scholarly Inquiry for Nursing Practice. 1996; 10:351-366. [PubMed: 9197160]

Mattay VS, Goldberg TE, Fera F, Hariri AR, Tessitore A, Egan MF, Kolachana B, Callicott JH, Weinberger DR. Catechol O-methyltransferase val158-met genotype and individual variation in the brain response to amphetamine. Proceedings of the National Academy of Science. 2003; 100:6186-6191.

Mattay VS, Tessitore A, Callicott JH, Bertolino A, Goldberg TE, Chase TN, Hyde TM, Weinberger DR. Dopaminergic modulation of cortical function in patients with Parkinson's disease. Annals of Neurology. 2002; 51:156-164. [PubMed: 11835371]

Mayberg HS, Starkstein SE, Sadzot B, Preziosi T, Andrezejewski PL, Dannals RF, Wagner HN Jr, Robinson RG. Selective hypometabolism in the inferior frontal lobe in depressed patients with Parkinson's disease. Annals of Neurology. 1990; 28:57-64. [PubMed: 2375634]

Mynett-Johnson LA, Murphy VE, Claffey E, Shields DC, McKeon P. Preliminary evidence of an association between bipolar disorder in females and the catechol-O-methyltransferase gene. Psychiatric Genetics. 1998; 8:221-225. [PubMed: 9861640]

Nutt JG, Burchiel KJ, Comella CL, Jankovic J, Lang AE, Laws ER Jr, Lozano AM, Penn RD, Simpson RK Jr, Stacy M, Wooten GF. factor, I.G.S.G.I.i.G.c.l.-d.n. Randomized, double-blind trial of glial cell line-derived neurotrophic factor (GDNF) in PD. Neurology. 2003; 60:69-73. [PubMed: 12525720]

Ohara K, Nagai M, Suzuki Y. Low activity allele of catechol-o-methyltransferase gene and Japanese unipolar depression. Neuroreport. 1998; 9:1305-1308. [PubMed: 9631418]

Reijnders JS, Ehrt U, Weber WE, Aarsland D, Leentjens AF. A systematic review of prevalence studies of depression in Parkinson's disease. Movement Disorders. 2008; 23:183-189. quiz 313. [PubMed: 17987654]

Rektorová I, Rektor I, Bares M, Dostal V, Ehler E, Fanfrdlova Z, Fiedler J, Klajblová H, Kulist'ák P, Ressner P, Svátová J, Urbánek K, Velisková J. Pramipexole and pergolide in the treatment of depression in Parkinson's disease: a national multicentre prospective randomized study. European Journal of Neurology. 2003; 10:399-406. [PubMed: 12823492]

Remy P, Doder M, Lees A, Turjanski N, Brooks D. Depression in Parkinson's disease: loss of dopamine and noradrenaline innervation in the limbic system. Brain. 2005; 128:1314-1322. [PubMed: 15716302]

Slaughter JR, Slaughter KA, Nichols D, Holmes SE, Martens MP. Prevalence, clinical manifestations, etiology, and treatment of depression in Parkinson's disease. Journal of Neuropsychiatry and Clinical Neuroscience. 2001; 13:187-196. 
Smolka MN, Schumann G, Wrase J, Grusser SM, Flor H, Mann K, Braus DF, Goldman D, Buchel C, Heinz A. Catechol-O-methyltransferase val158met genotype affects processing of emotional stimuli in the amygdala and prefrontal cortex. Journal of Neuroscience. 2005; 25:836-842. [PubMed: 15673663]

Starkstein SE, Preziosi TJ, Berthier ML, Bolduc PL, Mayberg HS, Robinson RG. Depression and cognitive impairment in Parkinson's disease. Brain. 1989; 112(Pt 5):1141-1153. [PubMed: 2804609]

Stefanova E, Potrebic A, Ziropadja L, Maric J, Ribaric I, Kostic VS. Depression predicts the pattern of cognitive impairment in early Parkinson's disease. Journal of the Neurological Sciences. 2006; 248:131-137. [PubMed: 16780884]

Tai CH, Wu RM. Catechol-O-methyltransferase and Parkinson's disease. Acta Medica Okayama. 2002; 56:1-6. [PubMed: 11873938]

Tessitore A, Hariri AR, Fera F, Smith WG, Chase TN, Hyde TM, Weinberger DR, Mattay VS. Dopamine modulates the response of the human amygdala: a study in Parkinson's disease. Journal of Neuroscience. 2002; 22:9099-9103. [PubMed: 12388617]

Troster AI, Paolo AM, Lyons KE, Glatt SL, Hubble JP, Koller WC. The influence of depression on cognition in Parkinson's disease: a pattern of impairment distinguishable from Alzheimer's disease. Neurology. 1995a; 45:672-676. [PubMed: 7723954]

Troster AI, Stalp LD, Paolo AM, Fields JA, Koller WC. Neuropsychological impairment in Parkinson's disease with and without depression. Archives of Neurology. 1995b; 52:1164-1169. [PubMed: 7492290]

Uekermann J, Daum I, Peters S, Wiebel B, Przuntek H, Muller T. Depressed mood and executive dysfunction in early Parkinson's disease. Acta Neurologica Scandinavica. 2003; 107:341-348. [PubMed: 12713526]

Veazey C, Aki SO, Cook KF, Lai EC, Kunik ME. Prevalence and treatment of depression in Parkinson's disease. Journal of Neuropsychiatry and Clinical Neuroscience. 2005; 17:310-323.

Wertman E, Speedie L, Shemesh Z, Gilon D, Raphael M, Stessman J. Cognitive disturbances in Parkinsonian patients with depression. Neuropsychiatry, Neuropsychology, and Behavioral Neurology. 1993; 6:31-37. 


\section{Facial Affect Naming Test}

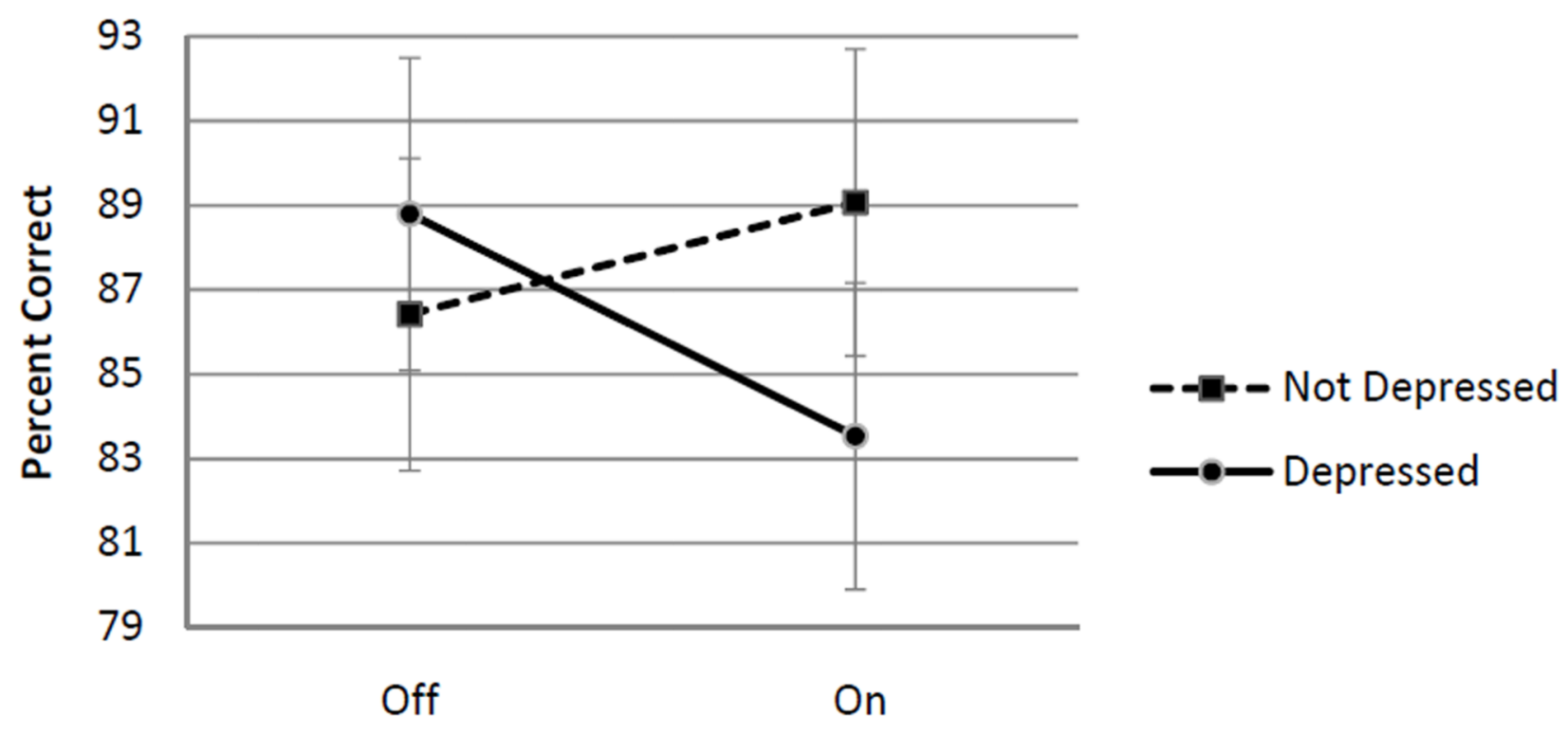

Anti-PD Medication Status

Figure 1. Dopaminergic Modulation of Facial Affect Recognition

displays a significant interaction between depression and medication status for the facial affect naming test $(\mathrm{p}=0.016)$ after co-varying for age and NART-R Full scale IQ scores. 


\section{Hopkins Verbal Learning Total Recall}

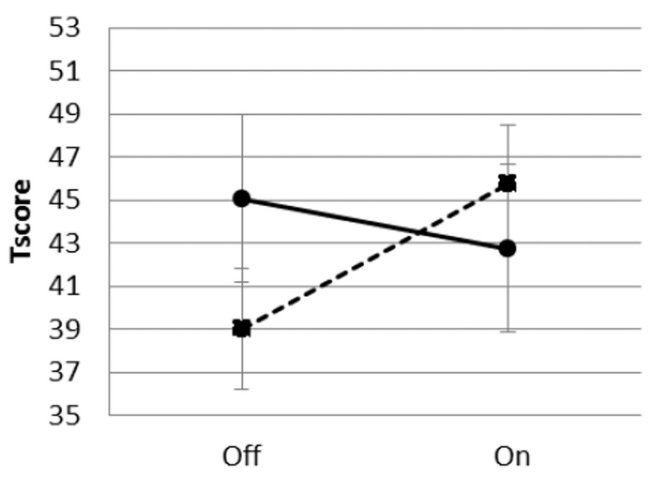

Anti-PD Medication Status
Hopkins Verbal Learning-Delayed Recall

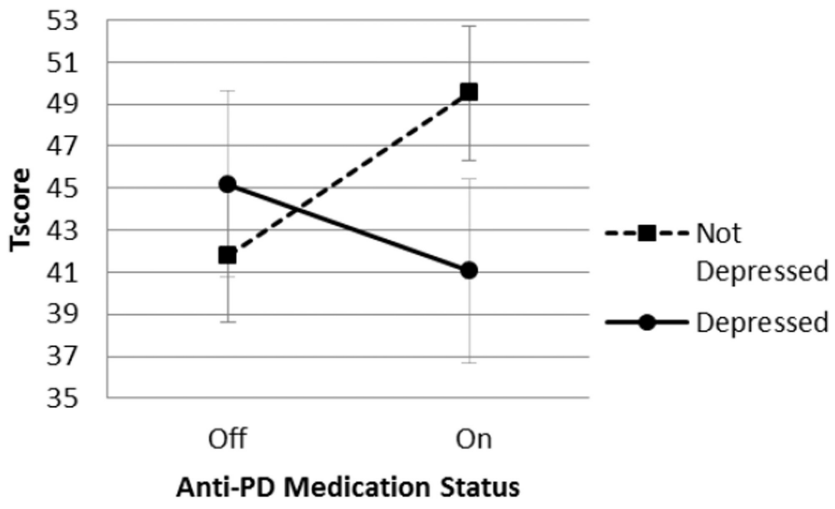

Figure 2. Dopaminergic Modulation of Verbal Memory

displays a significant interaction between depression and medication status for the Hopkins Verbal Learning-revised Total Recall $(\mathrm{p}=0.019)$ and Delayed Recall $(\mathrm{p}=0.010)$ after covarying for age and NART-R Full scale IQ scores. 
Table 1

Demographic and Clinical Data (on PD medication)

\begin{tabular}{lccc}
\hline & $\begin{array}{c}\text { Depressed } \\
\text { Parkinson's Patients } \\
\text { (SD) }\end{array}$ & $\begin{array}{l}\text { Non-Depressed } \\
\text { Parkinson's Patients } \\
\text { (SD) }\end{array}$ & p Value \\
\hline No. & 10 & 18 & NA \\
$\%$ Male & $70 \%$ & $61 \%$ & NS \\
Age y, mean (SD) & $55.2(7.0)$ & $68.4(8.2)$ & 0.0002 \\
Education & $15.6(2.3)$ & $16.0(3.1)$ & NS \\
Months since Diagnosis & $43.6(44.0)$ & $55.7(39.9)$ & NS \\
NART-R-FSIQ & $99.1(11.8)$ & $107.5(7.8)$ & 0.0321 \\
DRS-Scaled & $12.0(2.5)$ & $11.0(2.5)$ & NS \\
Hamilton Depression & $15.0(4.6)$ & $4.6(3.7)$ & $<0.0001$ \\
GDS-15 & $6.2(3.4)$ & $1.9(1.9)$ & 0.0002 \\
Hoehn \& Yahr & $2.1(0.5)$ & $2.1(0.4)$ & NS \\
UPDRS-Motor & $15.0(6.2)$ & $16.6(6.3)$ & NS \\
UPDRS-Tremor & $0.9(1.2)$ & $1.1(1.7)$ & NS \\
Schwab-England ADL & $84.0(13.5)$ & $89.2(11.5)$ & NS \\
$\%$ on DA Agonists & 60.0 & 61.1 & NS \\
Levodopa Equiv daily dose & $525.0(430.9)$ & $513.1(377.7)$ & NS \\
\hline
\end{tabular}

NART-R-FSIQ = National Adult Reading Test- revised, full scale IQ;

UPDRS = Unified Parkinson's Disease Rating Scale 